\title{
Body image and depression in girls with idiopathic precocious puberty treated with gonadotropin-releasing hormone analogue
}

\author{
Min-Seon Choi, MD, \\ Eun-Young Kim, MD, PhD
}

Department of Pediatrics, Chosun University School of Medicine, Gwangju, Korea
Received: 23 March, 2016

Revised: 6 May, 2016

Accepted: 12 August, 2016

Address for correspondence: Eun-Young Kim, MD, PhD

Department of Pediatrics, Chosun

University Hospital, Chosun

University School of Medicine, 365

Pilmun-daero, Dong-gu, Gwangju

61453, Korea

Tel: +82-62-220-3055,

Fax: +82-62-227-2704,

E-mail: sskey@chosun.ac.kr
Purpose: Precocious puberty (PP) is associated with psychological and behavioral problems. This study aimed to evaluate the perception of body image and depression in girls with PP receiving gonadotropin-releasing hormone (GnRH) analogue therapy.

Methods: From March to August 2013, 82 girls with PP receiving GnRH analogue therapy were enrolled. Height, weight, body mass index, and stages of pubertal development were assessed. Participants completed a series of questionnaires on their body image perception and pubertal self-assessment. The depression score was calculated using the Korean Kovacs' Children's Depression Inventory.

Results: The patients perceived their body to be more obese than the controls did. The mean depression score did not differ between the patients and controls. The mean depression scores according to Tanner stages (1: prepubertal, 2: early pubertal, and 3-5: mid to late pubertal stage) by self-assessment were $5.2 \pm 3.6$, $6.8 \pm 4.9$, and $11.4 \pm 10.1(P<0.05)$, respectively. The perception of overall body build and figure (\%) and the mean depression scores in patients were: dissatisfied (25.6\%, $9.7 \pm 7.8)$ and satisfied $(74.4 \%, 5.5 \pm 3.4)(P<0.05)$. In multiple linear regression analysis, self-T3 (Tanner stage $3-5$ by self-awareness) and dissatisfaction about overall body build and figure were found to significantly affect the depression score $(P<0.05)$.

Conclusion: The perception of pubertal status and satisfaction about height or weight are unrelated to objective physical findings. Patients with PP are prone to distorted perception about their body image and breast development. Such incorrect body image seems to contribute to depression score.

Keywords: Precocious puberty, Body image, Depression

\section{Introduction}

As physically mature individuals, teenagers face changes in social norms and expectations. To adapt to these changes, they often need to change their identity and self-awareness as well as responses. Therefore, puberty is a period of significant developments related to biological, psychological, and social problems. Abnormal maturational timing may lead to an increase in the risk for emotional and behavioral problems during adolescence. In particular, earlier pubertal maturation in girls may cause a number of problems compared with on-time or later maturation ${ }^{1)}$. Early maturation in girls provokes social changes and social chaos for which they may not be prepared ${ }^{2)}$.

Early maturing girls are more likely to experience body dissatisfaction and low self-esteem during adolescence ${ }^{3,4)}$. Furthermore, early puberty in girls has been reported as a risk factor for depression ${ }^{4,5)}$. The degree of physical maturity is related to low self-esteem during adolescence, which affects perception about body image and eating behavior ${ }^{6}$. Eating behavior, perception 
about body image, and depression are inter-related and are known to be affected by a number of factors such as biological, social, and psychological environments.

Although many studies have examined early maturity or puberty, little is known about body image and depression in girls with precocious puberty receiving treatment with gonadotropin-releasing hormone $(\mathrm{GnRH})$ analogues. This study aimed to evaluate the perception of body image and the degree of depression in girls with precocious puberty receiving $\mathrm{GnRH}$ analogue therapy.

\section{Materials and methods}

\section{Subjects}

From March to August 2013, we enrolled 82 girls who were diagnosed with idiopathic precocious puberty and were being treated with GnRH analogue therapy. All of them had received a GnRH analogue for at least 6 months. We excluded patients with any of the following conditions: congenital disease, chronic disease, precocious puberty due to organic brain disease, congenital adrenal hyperplasia, hypothyroidism, and iatrogenic precocious puberty. Thirty-seven girls without significant medical history who were of similar age as the patients were enrolled as controls. We obtained informed consent from the guardians of all the participants.

\section{Diagnosis and measurements}

Idiopathic precocious puberty was diagnosed when patients met the following criteria: (1) breast development over sexual maturity rating 2 before the age of $8,(2)$ accelerated bone maturation, and (3) basal luteinizing hormone (LH) level $\geq 0.6$ $\mathrm{IU} / \mathrm{L}$ and peak $\mathrm{LH}$ level $\geq 6.9 \mathrm{IU} / \mathrm{L}$ in the $\mathrm{LH}$ releasing hormone stimulation test. Bone age was assessed with the GreulichPyle method using plain radiographs of the left hand. Height was measured using a Harpenden Stadiometer (within 0.1 $\mathrm{cm}$ ). Body weight was measured using a standard weight scale with zero reset after the participants removed their shoes and coat (within $0.1 \mathrm{~kg}$ ). Body mass index (BMI) was defined as body weight divided by the square of the height. According to BMI, the participants were subdivided into the following 3 groups considering the age groups presented by the 2007 Korean Societies of Pediatrics: obese ( $\geq 95$ th percentile BMI), overweight ( $\geq 85$ th, $<95$ th percentile BMI), and normal weight $(<85$ th percentile BMI) by BMI percentile adjusted for age.

\section{Survey questionnaire}

The investigators surveyed the patients and their guardians using a questionnaire. The purpose of the survey was explained and instructions on completing the questionnaire were provided. Questionnaires were filled by patients and their guardians without the intervention of the investigators.
We prepared a questionnaire to address the subjects' perceptions on body image. In order to accurately evaluate selfawareness on breast development, the subjects of the study were shown pictures corresponding to Tanner stage $1-5^{7)}$ and were asked to choose the picture that best matched their breast development status. The answers for self-awareness of their breast development were classified as self-T1 (Tanner stage 1: prepubertal), self-T2 (Tanner stage 2: early pubertal), or self-T3 (Tanner stage 3-5: mid to late pubertal).

In addition, we investigated the perception of body image by asking the subjects whether they were satisfied with their current height and weight, and about the degree of satisfaction they had on overall body build and figure. The subjects were asked to select either yes or no for satisfaction on height and weight. The degree of satisfaction on body build and figure was chosen from five categories (very dissatisfied, somewhat dissatisfied, neutral, somewhat satisfied, and very satisfied). For assessing depression, we used the Korean Kovacs' Children's Depression Inventory $(\mathrm{K}-\mathrm{CDI})^{8}$. $\mathrm{K}$-CDI consists of 27 questions (total score range, 0 to 54). In accordance with K-CDI, the cutoff scores were as follows: 22-25 for mild depression, 26-28 for moderate depression, and 29-54 for severe depression (Cronbach $\alpha=0.884987$ ).

This study was approved by the Institutional Review Board of Chosun University Hospital (approval number: PMS 2013-017001).

\section{Statistical analysis}

Statistical analyses were performed using SAS ver. 9.3 (SAS Inc., Cary, NC, USA). Independent $t$-test, Fisher exact test, Kruskal-wallis test, Wilcoxon rank sums test, score test for trend, Spearman correlation analysis, and multiple regression analysis were used. $P<0.05$ was considered as statistically significant.

\section{Results}

\section{General information}

A total of 82 patients (mean age, $9.3 \pm 0.8$ years) were enrolled. The mean period of treatment was $13.22 \pm 8.27$ months. Breast development status of all patients and controls was Tanner stage 1.

The height, weight, and BMI of patients did not differ significantly from those of the 37 controls, but there was a statistically significant difference in the height standard deviations score (SDS), weight SDS, and BMI SDS between patients and the control group (Table 1).

\section{The perception of body image}

Regarding their own height, a majority of both patients and controls were found to be "satisfied" $(57.3 \%$ [ $n=47]$ vs. $62.2 \%$ $[\mathrm{n}=23]$ ). There were no statistical differences between groups regarding this measure. 
In response to the question about their weight, a majority of the patients answered that they were "dissatisfied" (52.4\%, $\mathrm{n}=43$ ), as opposed to the controls, in whom a majority answered that they were "satisfied" $(54.1 \%, n=20)$. However, there was no statistical difference between groups. In contrast, in the subanalysis of "dissatisfaction with weight," most of the patients thought that they were overweight $(86.0 \%, \mathrm{n}=37)$ and a majority of the controls thought they were underweight $(58.8 \%, \mathrm{n}=10)$. Compared to the control group, a significantly larger proportion of patients with dissatisfaction with weight thought they were overweight $(P=0.003)$.

For the question about satisfaction with overall body build and figure, 5 answer choices were provided: dissatisfaction (very dissatisfied, somewhat dissatisfied), neutral, and satisfaction (somewhat satisfied, very satisfied). Most of the patients and controls were "satisfied" or "neutral" and there was no statistical difference between groups (Table 2).

In response to the question about self-awareness of their breast development, many patients (43.9\%) thought they were Tanner 2 (even though all of them were Tanner 1 ). In contrast, the majority of controls (54.1\%) thought they were Tanner 1. The difference was not statistically significant $(P=0.0572)$.

\section{Subgroups of patients: normal weight vs. overweight}

Table 1. Demographic characteristics of patients and controls

\begin{tabular}{lccc}
\hline Variable & Patients $(\mathrm{n}=82)$ & Controls $(\mathrm{n}=37)$ & $P$-value \\
\hline Age $(\mathrm{yr})$ & $9.3 \pm 0.8$ & $9.1 \pm 1.8$ & 0.594 \\
Height $(\mathrm{cm})$ & $136.9 \pm 5.9$ & $133.8 \pm 13.4$ & 0.177 \\
Height SDS & $0.69 \pm 0.80$ & $0.22 \pm 0.96$ & 0.007 \\
Weight $(\mathrm{kg})$ & $33.8 \pm 6.1$ & $30.9 \pm 9.6$ & 0.092 \\
Weight SDS & $0.53 \pm 0.89$ & $-0.01 \pm 0.95$ & 0.003 \\
BMI $\left(\mathrm{kg} / \mathrm{m}^{2}\right)$ & $17.9 \pm 2.4$ & $16.9 \pm 2.6$ & 0.062 \\
BMI SDS & $0.31 \pm 0.93$ & $-0.18 \pm 1.09$ & 0.013 \\
\hline
\end{tabular}

Values are presented as mean \pm standard deviation.

SDS, standard deviation score; BMI, body mass index.

Table 2. Answers regarding the perception of body image by patients and controls

\begin{tabular}{|c|c|c|c|}
\hline Questions \& answer & $\begin{array}{l}\text { Patients } \\
(\mathrm{n}=82)\end{array}$ & $\begin{array}{l}\text { Controls } \\
(n=37)\end{array}$ & $P$-value \\
\hline Satisfaction for height & & & 0.619 \\
\hline Satisfaction & $47(57.3)$ & $23(62.2)$ & \\
\hline Dissatisfaction & $35(42.7)$ & $14(37.8)$ & \\
\hline Satisfaction for weight & & & 0.512 \\
\hline Satisfaction & $39(47.6)$ & $20(54.1)$ & \\
\hline Dissatisfaction & $43(52.4)$ & $17(45.9)$ & \\
\hline Satisfaction for weight ${ }^{a)}$ & & & 0.003 \\
\hline Underweight & $6(14.0)$ & $10(58.8)$ & \\
\hline Overweight & $37(86.0)$ & $7(41.2)$ & \\
\hline Satisfaction for body build and figure & & & 0.442 \\
\hline Satisfaction (or neutral) & $61(74.4)$ & $25(67.6)$ & \\
\hline Dissatisfaction & $21(25.6)$ & $12(32.4)$ & \\
\hline
\end{tabular}

Values are presented as number (\%).

a) Subanalysis of "dissatisfaction with weight."
Patients are subdivided into normal weight $(74.4 \%, \mathrm{n}=61)$, overweight $(20.7 \%, \mathrm{n}=17)$, and obese group $(4.9 \%, \mathrm{n}=4)$. And controls are subdivided into normal weight $(91.9 \%, \mathrm{n}=34)$, overweight $(5.4 \%, \mathrm{n}=2)$, and obese group $(2.7 \%, \mathrm{n}=1)$. The number of obese group was too small in patients and controls. The combined overweight and obesity were classified as overweight group. A majority the participants in both the normal weight group and overweight group answered that they were "satisfied" with their height (more than 57\% in both subgroups). However, for weight, a greater proportion of patients in the overweight subgroup chose "dissatisfaction" with their weight compared to the normal weight subgroup $(85.7 \%$ vs. $41.0 \%, P<0.001)$. Subanalysis of "dissatisfaction with weight" showed that participants in both the overweight $(100 \%, n=18)$ and normal weight subgroups $(75.0 \%, \mathrm{n}=18)$ thought themselves as being overweight. In addition, the overweight subgroup had a tendency to think of themselves as "fat" $(P=0.029)$.

In response to the question about satisfaction with overall body build and figure, more patients in the normal weight subgroup answered that they were "satisfied" than those in the overweight subgroup ( $82.0 \%$ vs. $52.4 \%, P=0.007$ ) (Table 3 ).

Subgroups of controls (normal weight vs. overweight) did not show any significant difference in perceptions on body image.

In response to the question about self-awareness of their breast development, overweight patients thought that their breast were more mature (Tanner 2 [47.6\%] or 3 [42.9\%]) compared to those in the normal weight group (Tanner 1 [42.6\%] or $2[42.6 \%])(P=0.001)$.

\section{Depression score}

There was no significant difference in the mean depression

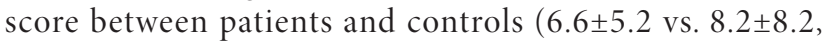
$P=0.276)$. In addition, there was no significant difference in

Table 3. Answers regarding the perception of body image by normal weight subgroups and overweight subgroups of patients

\begin{tabular}{|c|c|c|c|}
\hline Question \& answer & $\begin{array}{l}\text { Normal weight } \\
\quad(n=61)\end{array}$ & $\begin{array}{l}\text { Overweight } \\
(n=21)\end{array}$ & $P$-value \\
\hline Satisfaction for height & & & 0.985 \\
\hline Satisfaction & $35(57.4)$ & $12(57.1)$ & \\
\hline Dissatisfaction & $26(42.6)$ & $9(42.9)$ & \\
\hline Satisfaction for weight & & & 0.000 \\
\hline Satisfaction & $36(59.0)$ & $3(14.3)$ & \\
\hline Dissatisfaction & $25(41.0)$ & $18(85.7)$ & \\
\hline Satisfaction for weight ${ }^{a}$ ) & & & 0.029 \\
\hline Underweight & $6(25.0)$ & $0(0)$ & \\
\hline Overweight & $18(75.0)$ & $18(100)$ & \\
\hline $\begin{array}{l}\text { Satisfaction for body build } \\
\text { and figure }\end{array}$ & & & 0.007 \\
\hline Satisfaction (or neutral) & $50(82.0)$ & $11(52.4)$ & \\
\hline Dissatisfaction & $11(18.0)$ & $10(47.6)$ & \\
\hline
\end{tabular}

Values are presented as number (\%).

a) Subanalysis of "dissatisfaction with weight." 
depression score between the normal weight and overweight subgroups (6.4 \pm 4.9 vs. $7.1 \pm 6.1, P=0.936)$.

We analyzed the relationship between depression and satisfaction with height. Patients and controls dissatisfied with their height showed a higher mean depression score $(7.8 \pm 6.2)$ than patients and controls satisfied with their height (6.6 \pm 6.3$)$. However, the difference was not statistically significant.

Patients and controls dissatisfied with their weight also showed a higher mean depression score $(8.1 \pm 7.5)$ compared to patients and controls satisfied with their weight $(6.0 \pm 4.7)$. However, the difference was not statistically significant.

Patients and controls dissatisfied with their overall body build and figure showed a significantly higher mean depression score (10.3 \pm 9.7$)$ than patients and controls who were neutral or satisfied with their body type $(5.8 \pm 3.8, P=0.014)$.

Patients and controls who thought their breast was more mature than the actual appearance showed a significantly higher depression score $(P=0.02)$.

There was a significant correlation between depression score and Tanner stage at diagnosis (Spearman correlation coefficient $=0.24996, P=0.024)$. In addition, there was a correlation between Tanner stage at diagnosis and their selfawareness of breast development $(\gamma=0.5670, P=0.004)$.

A multiple linear regression was conducted to predict the depression score based on satisfaction about overall body build and figure, self-awareness of breast development, Tanner stage at diagnosis, satisfaction with height, satisfaction with weight, age, duration of treatment plus height SDS, weight SDS, and BMI SDS. Consequently, self-T3 (Tanner stage $3-5$ by selfawareness) $(P=0.032)$ and dissatisfaction about overall body build and figure $(P=0.031)$ statistically significantly predicted the depression score $\left(R^{2}=0.2422\right)$ (Table 4$)$.

\section{Discussion}

We investigated the association between perception of body image and degree of depression by comparing the depression score and satisfaction with weight, height, or overall body build and figure. Patients and controls who were dissatisfied with their overall body build and figure showed a significantly higher mean depression score than those who were neutral or satisfied with their overall body build and figure. In addition, patients and controls who thought that their breast were more mature than the actual appearance showed a significantly higher depression score. In multiple linear regression analysis, T3 (Tanner stages $3-5$ by self-awareness) and dissatisfaction about overall body build and figure significantly affected the depression score.

Puberty accompanies physical changes in the body such as breast development, appearance of pubic hair and/or menarche. When faced with rapid body changes, teenagers may become apprehensive of being unable to control their physical maturity ontheir $\mathrm{own}^{9}$. This might provoke negative affect, fear, and confusion especially in younger girls.

Previous studies have reported that early maturing girls tend to be dissatisfied with their height and/or weight. Many maturing girls hoped to be thinner, while early maturing boys tended to be satisfied with their height and/or weight. The more the girls matured, the higher the dissatisfaction with body weight reported by them. In addition, boys and girls showed a difference in the degree of recognition of puberty ${ }^{10}$. In this study, satisfaction with body weight was not associated with early maturation, but with a combination of other factors and overall pubertal maturity. The perception of their body image may be affected by physical, emotional, and social factors and/ or their actual body weight, BMI. The perception of their body weight is also associated with many complicated factors, rather than just the presence or absence of early maturity.

This study found no statistical difference in weight, height, and BMI between precocious pubertal patients and controls. Patients had a more obese body image and an exaggerated perception about their breast development regardless of the objective physical findings, though their height, weight, and BMI were not statistically different from the controls; these 2

Table 4. Multiple linear regression analysis using multiple factors and depression score

\begin{tabular}{|c|c|c|c|c|}
\hline Variable & Parameter estimate & Standard error & $t$-value & $\operatorname{Pr}>|t|$ \\
\hline Intercept & 10.66054 & 7.82166 & 1.36 & 0.178 \\
\hline Height dissatisfaction & 1.43029 & 1.49142 & 0.96 & 0.34 \\
\hline Weight dissatisfaction & -0.1869 & 1.30047 & -0.14 & 0.886 \\
\hline Overall body build and figure dissatisfaction & 3.07329 & 1.39424 & 2.2 & 0.031 \\
\hline Self-T2 & 0.32410 & 1.35904 & 0.24 & 0.812 \\
\hline Self-T3 & 3.82490 & 1.74679 & 2.19 & 0.032 \\
\hline Age & -0.06202 & 0.07243 & -0.86 & 0.395 \\
\hline Duration of treatment & 0.00673 & 0.06849 & 0.10 & 0.922 \\
\hline Height SDS & 2.71752 & 2.80966 & 0.97 & 0.337 \\
\hline Weight SDS & -4.60295 & 5.69149 & -0.81 & 0.422 \\
\hline BMI SDS & 2.40168 & 4.05132 & 0.59 & 0.555 \\
\hline Tanner 3 & 0.31544 & 1.34710 & 0.23 & 0.816 \\
\hline
\end{tabular}

Self-T2, Tanner stage 2 by self-awareness; self-T3, Tanner stage 3-5 by self-awareness; BMI, body mass index; SDS, standard deviation score.

F-value=1.95; R-square=0.2422; Adj R-square=0.1178. 
distorted body images were not independent of each other.

Social comparison is one of the most important factors influencing body awareness ${ }^{11)}$. The ideal images of celebrities such as thin women and muscular men affect the perception about body image in the general public. Such media exposure causes people to accept these images as the standard of attractiveness. Social comparison to these images brings a discrepancy in attractiveness between oneself and the other, negatively affecting the perception of the body image. Body satisfaction has typically been higher among males than among females, with adolescent girls tending to have more negative body image by the comparison among peers. When the perception and/or degree of their physical maturity are not consistent with peers, it may lead to teasing or induce social problems. In addition, seclusion or hyperactivity develops when a child notices that she differs from her peers. Early pubertal development is associated both with an initiation of smoking and drinking at a younger age and an increased likelihood of a lifetime diagnosis of substance abuse ${ }^{3)}$. The body image is affected by the way of recognizing their own overall body build and figure, rather than their actual overall body build and figure. Adolescent girls' body image is also influenced by the social relationship with their mothers (i.e., the same-sex parent), not fathers ${ }^{12}$.

There was no significant difference in mean depression scores between the patients and controls and between the normal weight and overweight subgroups. We commonly speculate the mental health status of overweight and obese girls to be poorer $^{13)}$. There was, however, no difference in depression scores between the normal weight and overweight groups in this study. There also was no significant difference in depression scores according to age.

Early puberty has been reported to be associated withdepression $^{5,14)}$. Various hormones secreted during puberty are known to cause depressive symptoms ${ }^{15)}$. However, the pubertal environment in which hormones are suddenly released, social factors, and the action of the hormones themselves are interrelated. These factors contribute to depression in combination, rather than alone ${ }^{16)}$. In particular, pubertal timing, rather than pubertal status, is the most important contributor to the emergence of depressive symptoms in adolescent girls ${ }^{2,17)}$. The most reasonable explanation for the effect of puberty timing on depressive symptoms is the psychological and social problems caused by the physical changes during early pubertal time $^{18)}$. For example, physically maturing girls have difficulty maintaining relationships with the same sex peers who have not matured at a similar rate. Early maturing girls may face environmentally difficulties even before they are emotionally and cognitively ready ${ }^{17}$. Menarche is a much more dramatic and rapid transition than other pubertal developments; therefore, experiencing menarche earlier than one's peers may raise a sense of emotional distance and isolation, leading to onset of depressive symptoms in early maturing girls than in those who physically mature later ${ }^{18)}$.

There are several limitations in our study. The number of patients and controls was not enough to allow a more detailed comparison of normal weight, overweight, and obesity. Many questions in the questionnaire were left unanswered despite explanation provided by the investigator and the help with filling out the questionnaire by guardians. In the future, we need to take account of the child's relationship with their parents, self-esteem, and other socioeconomic factors in girls in the prepubertal or pubertal state in which they worry and feel stress about their identity.

In this study, we found that patients have a more obese body image and exaggerated perception about their breast development regardless of the actual physical findings. The wrong perception of body image seems to contribute to depression score. The distorted body image can be corrected by instilling better understanding of physical development in girls with precocious puberty. Moreover, psychological encouragement and education is useful to correct patients' body image of precocious puberty.

\section{Conflict of interest}

No potential conflict of interest relevant to this article was reported.

\section{Acknowledgments}

This study was supported by grants from the Clinical Medicine Research Institute at Chosun University Hospital (2013)

\section{References}

1. Mendle J, Turkheimer E, Emery RE. Detrimental psychological outcomes associated with early pubertal timing in adolescent girls. Dev Rev 2007;27:151-71.

2. Rierdan J, Koff E. Depressive symptomatology among very early maturing girls. J Youth Adolesc 1991;20:415-25.

3. Graber JA, Lewinsohn PM, Seeley JR, Brooks-Gunn J. Is psychopathology associated with the timing of pubertal development? J Am Acad Child Adolesc Psychiatry 1997;36:1768-76.

4. Hayward C, Killen JD, Wilson DM, Hammer LD, Litt IF, Kraemer HC, et al. Psychiatric risk associated with early puberty in adolescent girls. J Am Acad Child Adolesc Psychiatry 1997;36:255-62.

5. Kaltiala-Heino R, Kosunen E, Rimpelä M. Pubertal timing, sexual behaviour and self-reported depression in middle adolescence. J Adolesc 2003;26:531-45.

6. O'Dea JA, Abraham S. Improving the body image, eating attitudes, and behaviors of young male and female adolescents: a new educational approach that focuses on self-esteem. Int J Eat Disord 2000;28:43-57.

7. Hall CH, Burstein GR. Adolescent development. In: Kliegman RM, Stanton BF, St. Geme JW III, Schor NF, 
Behrman RE, editors. Nelson textbook of pediatrics. 20th ed. Philadelphia: Elsevier Saunders, 2015:928.

8. Cho SC, Lee YS. Development of the Korean form of the Kovacs' Children's Depression Inventory. J Korean Neuropsychiatr Assoc 1990;29:943-56.

9. Abraham S, O'Dea JA. Body mass index, menarche, and perception of dieting among peripubertal adolescent females. Int J Eat Disord 2001;29:23-8.

10. Duncan PD, Ritter PL, Dornbusch SM, Gross RT, Merrill Carlsmith J. The effects of pubertal timing on body image, school behavior, and deviance. J Youth Adolesc 1985;14:227-35.

11. Carlson Jones D. Body image among adolescent girls and boys: a longitudinal study. Dev Psychol 2004;40:823-35.

12. Bukowski WM, Sippola LK, Newcomb AF. Variations in patterns of attraction to same- and other-sex peers during early adolescence. Dev Psychol 2000;36:147-54.

13. Wardle J, Cooke L. The impact of obesity on psychological well-being. Best Pract Res Clin Endocrinol Metab 2005; 19:421-40.

14. Stice E, Presnell K, Bearman SK. Relation of early menarche to depression, eating disorders, substance abuse, and comorbid psychopathology among adolescent girls. Dev Psychol 2001;37:608-19.

15. Angold A, Costello EJ, Erkanli A, Worthman CM. Pubertal changes in hormone levels and depression in girls. Psychol Med 1999;29:1043-53.

16. Brooks-Gunn J, Warren MP. Biological and social contributions to negative affect in young adolescent girls. Child Dev 1989;60:40-55.

17. Ge X, Conger RD, Elder GH Jr. Pubertal transition, stressful life events, and the emergence of gender differences in adolescent depressive symptoms. Dev Psychol 2001;37:40417.

18. Petersen AC, Sarigiani PA, Kennedy RE. Adolescent depression: Why more girls? J Youth Adolesc 1991;20:24771 . 